There is at present some difficulty in obtaining the genuine neat'sfoot oil. From the butchers, it is obtained too much mixed with impurities; from many druggists, mixed with so-called nut-oil; from some, too refined, having had almost all its stearine removed. In this so-styled very pure form, I find it disagrees with the stomach. In this, as in the cod-liver oil, and, probably, all other animal oils, a large proportion of stearine promotes the digestibility of the oil. The suitable kind of neat's-foot oil is that which is merely freed from foreign particles, yellowish brown in colour, and opaque and thick with stearine, like honey not over clear. ${ }^{1}$

I am indebted to Mr. Walker, formerly of Bloomsbury Square, for suggesting the use of neat's-foot oil, in a case where the cod-liver oil could not be made to agree with the patient. It is, however, by no means an entirels new remedy. I learn from a lady, who is said to have had all the symptoms of consumption thirty years ago, that one Samuel Braunston, of Shuckborough, Warwickshire, was noted for professing to cure all sorts of diseases with neat's-foot oil. He wished to administer his remedy to my informant, but she declined.

To ensure a fair trial, I would suggest that care should be taken that the oil is genuine, but not what the druggists call " exceedingly pure"; that the dose to begin with be small-a teaspoonful twice a day - and increased by degrees to any quantity that may be desirable, and always taken when there is food in the stomach.

Torquay, April 15, 1852.

\title{
REMARKS ON DR. MARSHALL HALL'S THEORY OF THE RELATION OF LARYNGISMUS TO EPLLEPSY; AND ON ITS TREATMENT BY NITRATE OF BILYER APPLIED IN SOLUTION TO THE GLOTTLS.
}

By EBEN. WATSON, A.M., M.D., Fellow of the Faculty of Physicians and Surgeons of Glasgow; and Professor of the Institutes of Medicine in Anderson's University.

\& 122. Observation teaches us that laryngismus, more or less severe, intervenes as the essential cause of all that is convrulsive and most formidable in epilepsy.

"251. The effects of laryngismus are superseded by tracheotomy."

Croontas Lectures for 1852.

AwY suggestion on such an important subject as the theory and treatment of epilepsy, especially when emanating from one, who, like Dr. Marshall Hall, has long devoted much attention to that class of disease, is well worthy the careful consideration of every practical physician. Nor can any one fail to see that, if Dr. Hall's statements be correct, a most important revolution must take place in our treatment of the disease in question, and a much more hopeful prospect will be opened up to its unhappy victims.

1 In point of economy, neat's-foot oil is rather less expensive than cod-liver oil. The wholesale manufacturers charge it 1s. a pint; the wholesale druggists, 18.4d.; the Torquay druggists, 2s.; the London druggists, (at least some of them), 6s., under the name of olerus bubuli. 
I cannot but admire the way in which this distinguished physician has followed what he calls "living pathology"; and there can be no doubt that if others were as capable as he is, of improving their opportunities of observation, we should soon arrive at many important results. In no other way, moreover, can a true theory of any disease of the nervous system be arrived at: for our means of investigating its structural changes after death are not much to be depended upon, even in the present advanced state of anatomical research. Dr. Hall looks at the phenomena of the disease, as they present themselves in the living subject; he notes the flushing of the countenance, the disturbed breathing, the convulsions, the stupor, etc., which occur in an epileptic paroxysm, and he endeavours to trace them to a sufficient cause, in accordance with previously ascertained laws of the animal economy. The result is, that he traces all the events of the epileptic paroxysm to spasmodic closure of the glottis, or laryngismus, as he calls it; which, according to him, causes an "impediment to the flow of blood from the brain and from the upper part of the spinal marrow, and, as a further consequence, all the direr forms and effects of this dire disease, viz. convulsion, convulsive falling, or rather dashing, to the ground, etc. etc."

Now there can, I think, be little doubt in the mind of any one, who has attended carefully to the symptoms of this distressing state, that laryngismus is indeed a rery early, if not the first, occurrence in every severe epileptic fit; and that, supposing it to have occurred, it must be regarded as the cause of many of the subsequent events. But this does not amount to Dr. Hall's statement, of the correctness of which, indeed, I am not quite persuaded, viz. that laryngismus is " the essential cause of the epileptic convulsion". It, in fact, rather seems to me to be an early part of that convulsion. The glottidean muscles appear to be among the first to become spasmodically contracted; and the effect of this contraction upon the nervous centres, as well as the continued violence of the disease, tend to keep up that contraction, and to aggravate the mischief which, undoubtedly, it is capable of accomplishing.

In some of Dr. Todd's experiments, convulsions were produced after the windpipe had been opened; and I have myself seen a patient die convulsed, from an overdose of atrychnia, while a trachea tube held the glottis expanded, and admitted of the inflation of the lungs. The cause of death, in this case, was obvious, especially on post-mortem examination; and an account of the whole case may be found in the Edinburgh Monthly Journal of Medicine for 1845. I merely refer to it in this place to show, not, as Dr. Todd imagined that his experiments proved, the impossibility of laryngismus ever producing convulsions, but that the former cannot be "the eseential cause" of the latter; or, in other words, that convulsion may occur independently of laryngismus, and therefore it follows, that there is no necessary connexion between the two states, as cause and effect.

When, again, it is remembered how often laryngismus of the severest kind occurs in cases of hooping cough, of spasmodic croup, and even of apoplexy, without the occurrence of any other convulsive contractions, I think it will be granted, that Dr. Hall is somewhat too extreme, when he says that "laryngismus intervenes as the essential cause of 
all that is convulsive in epilepsy". Why, what is laryngismus itself, if it be not convulsive? And if so, it remains to be explained what is the cause of the laryngismus, ere we have a perfect theory of epilepsy.

It may be, that the original cause of the malady is in the brain, or in the cord; or it may be some general affection of the nerrous system, some morbid state of the nervous fluid, or some derangement of the nervous particles. I think it is useless to speculate on such hypotheses, without more solid data than we at present possess. Nor can I regard Dr. Todd's comparison of the state of the brain in these cases, with that of a highly-charged Leyden jar, the disruptive discharge of the latter representing the paroxysm of the former. I cannot regard such an hypothesis, emanating though it does from so excellent a physiologist, but as a warning against the slightest departure from strict induction in framing our theories of disease.

But, although I cannot assent to the unmodified proposition of Dr. Marshall Hall, as to the cause of epilepsy, yet I thoroughly agree with him in his statement, that laryngismus is the cause of much-I dare not say, with him, of all-that is dangerous or formidable in epilepsy. In this, however, is the great merit of Dr. Hall's view of the subject; for it matters comparatively little to the patient on what theory of its remote cause his disease is treated, if only that which is formidable therein be removed. And I think Dr. Hall has proved that, if the laryngeal spasm be prevented, the fits will, at all events, be much diminished in frequency, as well as in severity :- " the grand mal will become the petit mal." Now, this is no mean attainment; and I believe it is the result of rigid and correct observation of phenomena as they occur-a result which could never have followed the construction of the most ingenious hypothesis. For, though it still remains true, in my opinion, that we cannot altogether prevent the convulsions, yet it does scem possible to rob them of a great part of their terrors : in other words, though we may not yet be in a position to cure epilepsy, still we may remove laryngismus, which is the most dangerous part of the epileptic fit. Now this, according to Dr. Marshall Hall, is to be accomplished by the performance of tracheotomy; and I have no hesitation in stating my entire concurrence with him as to the necessity of such a proceeding, in certain severe cases, in which life may be threatened from continued closure of the glottis during the epileptic paroxysm. But the question of its propriety in a much larger number of cases, in which a longer or shorter interval of freedom from spasm occurs, is more difficult, and, in fact, is different in many respects. The operation is not then performed with the immediate view of saving life, but prospectively, with the view of mitigating the severity of the fits; and I believe that, in such circumstances, few patients would submit to this heroic remedy.

The treatment which I would now propose in its stead, is of a much milder and more innocent nature : and one which, $I$ believe, will in most cases prove equally efficacious. It is simply the application of a solution of the nitrate of silver, varying in strength with the requirements of the case, to the glottis of the epileptic patient, with the view of diminishing the nervous excitability of the part in question. A similar treatment has been found by me remarkably successful in alleviating and removing, in a short time, the susceptibility of the patient 
to laryngismus, in cases of hooping cough, and of spasmodic croup (laryngismus stridulus); nor can I see any reason why a similar result should not ensue in chronic cases of epilepsy. In the latter, the laryngeal spasm may occur at longer intervals, though by no means always so; and it may be accompanied by much graver results to the patient's mental, as well as bodily health : but the mechanism of the morbid phenomenon is precisely similar in both instances, and agents which affect it in the one case, may, or rather must, affect it in the other.

Nor have I been slow to test, by actual trial, this means of alleviating the severity of the epileptic paroxysm; and I may now be permitted to give the chief features of the following case in point.

Early in January of this year (1852), I was called to a young lady, who had for several years suffercd very frequent attacks of epilepsy, and when I first saw her, she had but very short and uncertain intervals between the fits. These were very severe, and presented the usual characters of the disease in its most marked form.

Her bowels were thoroughly cleared out with croton-oil, and the cold bath was used with good effect. The fits became less frequent, though almost equally severe when they did occur. The valerianate of zinc and galvanism were then added to the cold bath, and due regulation of the bowels. I now, moreover, began to touch the glottis with a solution of one scruple of nitrate of silver in an ounce of water. This was continued regularly every day for a fortnight, and afterwards for some weeks with longer intervals between the applications. By the middle of February, the fits had quite changed their character, being more like short faints than the regular convulsive paroxysm; and they have since then occurred very much less frequently. The patient has greatly improved in general health, and in activity of mind; and she has lost much of that dread of the disease which formerly rendered her existence miserable.

It is very true that this is but a single instance, and that the present farourable state of the patient may not be permanent. Yet, seeing that the remedy has, even in one case, been followed by such admirable results, seeing that it is in itself most innocent, and so reasonable in theory, surely I am warranted in suggesting it for trial by my fellowpractitioners. Nor ought it to be forgotten that, although I can only at present furnish one instance of its efficacy in curing epileptic laryngismus, abundance of proof might be adduced, to show its power to subdue laryngismus in other cases. In those of hooping cough alone, since I first proposed this plan in the Edinburgh Monthly Journal of Medical Science for 1849 , I have treated to a conclusion some fiftyseven cases; and $M$. Joubert, of Cherion, has treated sixty-eight. (See Edinburgh Monthly Journal for March, p. 256.) Now, in all these hundred and twenty-five cases of heoping cough, the laryngismus was speedily cured, except in eight cases, which resisted the treatment, but were none the worse for it; for not one death occurred among them.

It may likewise be objected to the proposal I have made in this short paper, that the topical treatment of the larynx is carried too far in the present day; that it is supposed by some to be capable of curing almost every laryngeal affection. Now, I am as much opposed as any one can be to this indiscriminate use of the topical, or of any other 
plan of treatment. But let us not, on account of the erroneons application of a remedy, shut our eyes altogether to its virtues in appropriate cases. From no inconsiderable experience of the application of solutions of nitrate of silver to the larynx, I am quite convinced that it will assist most materially in the reduction of œdema of that organ, whether acute or chronic, in the removal of any of the numerous varieties of asthenic inflammation of its mucous lining; and lastly, that it will, by a prolonged employment, free the patient from susceptibility of laryngismus.

But need I say, that neither the solution of caustic, nor any other local remedy can be relied on, if used alone. Were $I$ indeed able to agree with Dr. Marshall Hall, that laryngismus is the essential cause of the epileptic convulsions, then I might say that the means proper for its removal constitute the rational treatment of that disease. I am not, however, in this position; and while I grant the importance of laryngismus as a cause of formidable symptoms, I regard it as the effect of a previous morbific agency, of the precise nature of which we are totally ignorant. But this we know, that in all cases of epilepsy, the general health is, in the commencement of the disease, much and variously disturbed, and that, during its whole future course, frequent derangements of the digestive and vascular systems are most apt to occur. Whether this may arise from the organic nerve participating in the vitiation of the cerebro-spinal system, or whether the disease be essentially one of the former system of nerves affecting the brain and medulla only secondarily, by causing abnormal nutrition of their substance, it is not our present purpose to inquire. It is sufficient that such derangements exist; they ought not to be neglected in the treatment of the disease, more especially as we cannot trust to any measures directed against the supposed seat of the morbific cause.

My object in making the preceding remarks has been threefold, viz.:

1. To assent to the following modification of Dr. Marshall Hall's theory of epilepsy, viz., that laryngismus is an early occurrence in every severe epileptic seizure, and that it is the essential cause of much that is formidable therein.

2. To state it as my opinion, that Dr. Hall is entitled to the gratitude of the profession, especially in this instance, for having directed attention to an organ, derangement of whose functions is one, if not the chief, cause of danger to the epileptic patient; an organ, moreover, which lies within reach of efficient remedies. And,

3. To propose, as a substitute for tracheotomy in the less urgent class of cases, the application of a solution of nitrate of silver to the interior of the larynx, with the view of exhausting the excitability of the laryngeal nerves, and thus rendering the patient, in a longer or shorter time, insusceptible of laryngismus.

Glasgow, June 1852. 